\title{
КЛИНИЧЕСКИЕ И МОЛЕКУЛЯРНО-ГЕНЕТИЧЕСКИЕ ХАРАКТЕРИСТИКИ ПАЦИЕНТОВ С МОРФОЛОГИЧЕСКОЙ КАРТИНОЙ ВРОЖДЕННОЙ СТЕРЖНЕВОЙ МИОПАТИИ
}

А. А. Козина ${ }^{1,2,5}$, П. А. Шаталов ${ }^{3,5}$, Т. И. Баранич1', С. Б. Артемьева ${ }^{3}$, А. Г. Куприянова ${ }^{3}$, Н. В. Барышникова ${ }^{1,5}$, А. Ю. Красненко1,5, В. В. Ильинский ${ }^{1,2,5}$, В. С. Сухоруков ${ }^{1,4}$

'Российский национальный исследовательский медицинский университет имени Н. И. Пирогова, Москва, Россия

2 Научно-исследовательский институт биомедицинской химии имени В. Н. Ореховича, Москва, Россия

${ }^{3}$ Научно-исследовательский клинический институт педиатрии имени академика Ю. Е. Вельтищева,

Российский национальный исследовательский медицинский университет имени Н. И. Пирогова, Москва, Россия

${ }^{4}$ Научный центр неврологии, Москва, Россия

${ }^{5} \mathrm{OОО}$ «Генотек», Москва, Россия

Врожденные стержневые миопатии - это клинически и генетически гетерогенная группа врожденных миопатий, общий гистопатологический признак которых - наличие участков с уменьшенной окислительной активностью при биопсии мышц. Взаимосвязь клинико-генетических, патогенетических и морфологических характеристик этой группы миопатий до конца не изучена. Целью исследования было проанализировать соответствие клиникоморфологических характеристик пациентов с врожденными миопатиями/миодистрофиями и результатов экзомного секвенирования, полученных методами массового параллельного секвенирования (MPS). В исследовании участвовали 8 детей (2 мальчика и 6 девочек 3-14 лет). Морфологический анализ проводили с помощью световой и электронной микроскопии. Молекулярно-генетический анализ проводили с помощью МРS на платформе HiSeq2500. Мутации были обнаружены в 87,5\% случаев (у 7 из 8 обследованных): у 6 обследованных (8 мутаций) - в генах, ответственных за врожденные стержневые миопатии, и у одного пациента (2 мутации) - в гене LAMA2, ответственном за мерозин-негативную мышечную дистрофию. Доли пациентов с выявленными мутациями в гене RYR1 и мутациями в гене SEPN1 одинаковы и составили 42,86\% среди пациентов с мутациями. Из 10 мутаций, выявленных у обследованных пациентов, 3 мутации описаны впервые: в гене RYR1 - c.7561G>A; в гене SEPN1 - с.485C>A; в гене LAMA2 - p.Cys1136Arg. Совокупность клинических и морфологических признаков, характерных для стержневых миопатий, не позволяет ограничить молекулярно-генетический поиск причины заболевания генами RYR1 и SEPN1, что приводит к необходимости исследовать другие гены, ответственные за развитие врожденных миопатий/миодистрофий, с использованием современных молекулярно-генетических методов.

Ключевые слова: врожденные миопатии центрального стержня, врожденные многостержневые миопатии, ген RYR1, ген SEPN1, ген LAMA2, мышечная биопсия, экзомное секвенирование

Информация о вкладе авторов: А. А. Козина - анализ литературы, интерпретация данных экзомного секвенирования, анализ данных, подготовка рукописи; П. А. Шаталов - сбор данных, проведение морфологического исследования, подготовка рукописи; Т. И. Баранич - проведение морфологического исследования; С. Б. Артемьева - сбор клинических данных, неврологический осмотр пациентов; А. Г. Куприянова - сбор клинических данных; Н. В. Барышникова - анализ литературы, интерпретация данных экзомного секвенирования, анализ данных, подготовка рукописи; А. Ю. Красненко - проведение экзомного секвенирования; В. В. Ильинский — проведение экзомного секвенирования; В. С. Сухоруков планирование исследования, сбор данных.

Соблюдение этических стандартов: исследование одобрено этическим комитетом ФГБОУ ВО РНИМУ имени Н. И. Пирогова (протокол № 172 от 19 февраля 2018 г. ); все участники исследования или их законные представители подписали добровольное информированное согласие.

$\triangle$ Для корреспонденции: Анастасия Александровна Козина

Наставнический переулок, д. 17, стр. 1, г. Москва, 105120; doctor@genotek.ru

Статья получена: 07.02.2019 Статья принята к печати: 19.04.2019 Опубликована онлайн: 30.04.2019

DOI: $10.24075 /$ vrgmu.2019.034

\section{CLINICAL AND MOLECULAR-GENETIC PROFILES OF PATIENTS WITH MORPHOLOGICAL INDICATIONS OF CONGENITAL MULTICORE MYOPATHY}

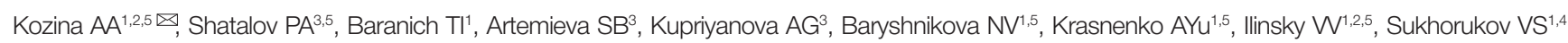

${ }^{1}$ Pirogov Russian National Research Medical University, Moscow, Russia

2 Orekhovich Institute of Biomedical Chemistry, Moscow, Russia

${ }^{3}$ Veltischev Research and Clinical Institute for Pediatrics, Pirogov Russian National Research Medical University, Moscow, Russia

${ }^{4}$ Research Center of Neurology, Moscow, Russia

${ }^{5}$ Genotek Ltd., Moscow, Russia

Congenital core myopathies are a clinically and genetically heterogenous group of congenital myopathies that share a specific histopathological feature: areas of reduced oxidative activity in muscle fibers. The relationship between clinical, genetic and morphological characteristics of this group of disorders remains understudied. The aim of this work was to compare clinical presentations and morphological phenotypes of patients with congenital myopathies/myodystrophy to the data yielded by massively parallel exome sequencing. Eight children were included in the study: 2 boys and 6 girls aged 3 to 14 years. Their biopsy material was analyzed by light and electron microscopy. Sequencing was performed on HiSeq2500. Mutations were detected in 7 (87.5\%) of 8 participants. Six children had 8 mutations in the genes associated with congenital core myopathies; one patient had 2 mutations in the LAMA2 gene implicated in merosin-deficient muscular dystrophy. The proportions of patients with mutations in RYR1 and SEPN1 were equal (42.86\%). Of 10 detected mutations, 3 had not been previously described, including c.7561G>A in RYR1, c.485C >A in SEPN1 and p.Cys1136Arg in LAMA2. The clinical and morphological features of core myopathies suggest that genetic causes of this group of disorders should not be limited to RYR1 and SEPN1 genes only. This necessitates the search for and the study of other genes implicated in congenital myopathies or myodystrophy using state-of-the-art molecular genetic tools.

Keywords: congenital central core disease, congenital multicore myopathies, RYR1 gene, SEPN1 gene, LAMA2 gene, muscle biopsy, exome sequencing

Author contribution: Kozina AA — literature analysis, analysis and interpretation of exome sequencing data, manuscript preparation; Shatalov PA — data acquisition, microscopy, manuscript preparation; Baranich TI — microscopy; Artemieva SB — medical histories and neurological examinations;

Kupriyanova AG — clinical data acquisition; Baryshnikova NV — literature analysis, analysis and interpretation of exome sequencing data, manuscript preparation; Krasnenko AYu — exome sequencing; llinsky W — exome sequencing; Sukhorukov VS — study design, data acquisition.

Compliance with ethical standards: the study was approved by the Ethics Committee of Pirogov Russian National Research Medical University (Protocol № 172 dated February 19, 2018). All participants or their legal representatives gave informed consent to participate.

$\triangle$ Correspondence should be addressed: Anastasia A. Kozina

Nastavnichesky per. 17, bld. 1, Moscow, 105120; doctor@genotek.ru

Received: 07.02.2019 Accepted: 19.04.2019 Published online: 30.04.2019

DOI: 10.24075/brsmu.2019.034 
Врожденные миопатии - это клинически и генетически гетерогенная группа нервно-мышечных заболеваний со сложным патогенезом, неоднородной клинической картиной и разными типами наследования [1]. Функциональная недостаточность мышечной ткани при заболеваниях данной группы проявляется на фоне развития специфических патологических структур в мышечных волокнах при отсутствии миодистросических процессов в них [2].

На основании морфологической картины биопсийного материала различают несколько форм врожденных структурных миопатий, самые распространенные из которых - болезнь центрального стержня, немалиновая миопатия, многостержневая миопатия, центронуклеарная миопатия, описаны как классические формы [2].

Каждая морфологическая форма включает несколько генетических вариантов, различающихся и по тяжести клинической картины, и по типу наследования, что имеет значение для тактики ведения пациентов и медикогенетического консультирования семьи.

Оценка распространенности отдельных морфологических форм и генетических вариантов врожденных структурных миопатий, их истинного вклада в структуру симптомокомплекса «вялый ребенок», клиническая дифференциальная диагностика, а также классификация по-прежнему затруднены. Это обусловлено высокой генетической гетерогенностью и редкостью отдельных вариантов, перекрыванием клинических симптомов при нервно-мышечных заболеваниях, формирующих симптомокомплекс «вялый ребенок», ограничениями использования молекулярно-генетических методов диагностики.

Несмотря на то что изучать врожденные структурные миопатии начали с описания болезни центрального стержня еще в 1956 г., до сих пор до конца не изучены этиопатогенез и клинико-генетические корреляции при врожденных миопатиях, сопровождающихся формированием морфологической картины в виде «стержней».

Общей морфологической особенностью стержневых миопатий является наличие области сниженной окислительной активности ферментов в мышечных волокнах первого типа, определяемой при гистохимическом анализе, в сочетании с дезорганизацией саркомеров и почти полным истощением митохондрий [3, 4].

Выделяют две основные формы стержневых миопатий: болезнь центрального стержня и многостержневую миопатию.

Согласно литературным данным, основными причинами развития наследственных форм стержневых миопатий являются мутации в генах, кодирующих два белка саркоплазматического ретикулума: рианодиновый рецептор $(R Y R 1)$, обеспечивающий работу канала высвобождения кальция, и селенопротеин N (SEPN1) [5, 6].

Ген рианодинового рецептора (RYR1) локализован на хромосоме 19q13.1 и включает 106 экзонов. Рианодиновый рецептор представляет собой рецепторуправляемый $\mathrm{Ca}^{2+}$-канал, расположенный в мембране эндоплазматического ретикулума и регулирующий выход из него кальция. В скелетной мышечной ткани рианодиновый рецептор локализован в мембране поперечных цистерн саркоплазматического ретикулума и связан с дигидропиридиновым рецептором на инвагинациях плазмалеммы в Т-трубочках. Сигнал, приходящий по сарколемме за счет этой связи, воздействует на саркоплазматический ретикулум, вызывая выброс кальция, необходимого для мышечного сокращения [7-9]. Мутации в гене рианодинового рецептора (RYR1) встречаются чаще, чем мутации в гене селенопротеина N (SEPN1), и связаны с развитием нескольких патологических состояний, в первую очередь болезни центрального стержня (Central core disease, OMIM 117000) с аутосомно-доминантным и аутосомно-рецессивным типами наследования и реже многостержневой миопатии (Multiminicore disease, OMIM 255320) с аутосомно-рецессивным типом наследования $[10,11]$. Мутации в гене RYR1 ассоциированы также c повышенным риском злокачественной гипертермии (Malignant hyperthermia susceptibility 1, ОМІM 145600) c аутосомно-доминантным типом наследования фармакогенетической предрасположенности к тяжелой и потенциально смертельной побочной реакции в ответ на применение летучих анестетиков и/или миорелаксантов [12].

В основе патогенеза болезни центрального стержня лежат ультраструктурные изменения в центральных зонах скелетных мышечных волокон, а также отсутствие в них функциональной активности, в первую очередь митохондриальных ферментов. Гистологические характеристики этих зон («стержней»), не схожие с таковыми в периферических участках волокна, служат одним из основных диагностических критериев заболевания [13] (рис. 1 и 2). Болезнь центрального стержня обычно развивается в раннем детском возрасте. К характерным признакам относят задержку моторного развития, снижение мышечного тонуса, слабость проксимальных отделов мышц (при этом лицевая мускулатура не страдает). Для данного заболевания характерны также такие скелетные нарушения, как врожденный вывих бедра и сколиоз. Мышечная слабость с возрастом не прогрессирует.

Ген SEPN1 локализован на хромосоме 1р36-р35, включает 13 экзонов и кодирует белок селенопротеин N, представляющий собой гликопротеин, расположенный в эндоплазматическом ретикулуме и выступающий в роли медиатора селена, который входит в состав различных защитных и метаболических систем. Кроме того, он принимает участие в поддержании кальциевого гомеостаза в мышечной ткани путем обеспечения деятельности окислительных ферментов и контроля окислительного состояния рианодиновых рецепторов.

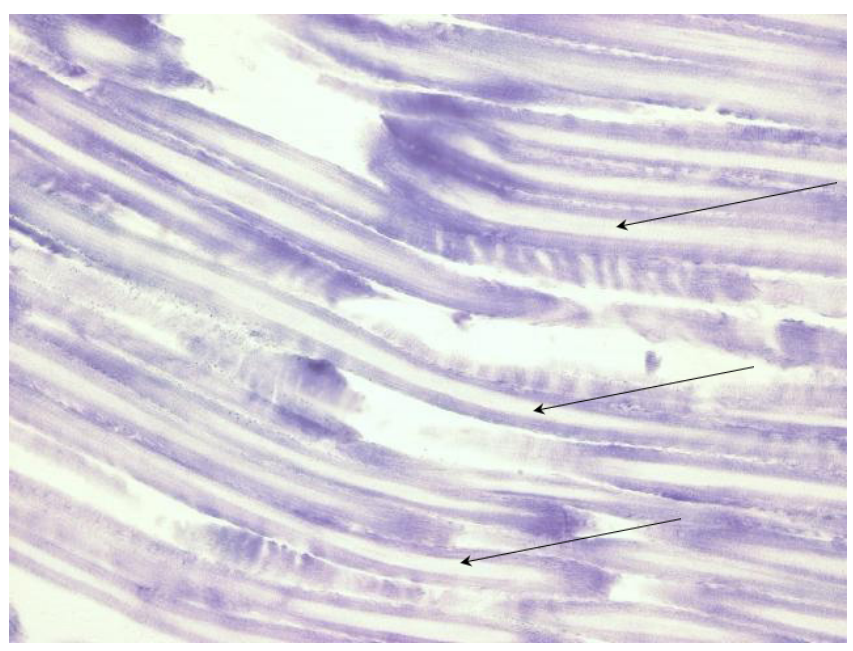

Рис. 1. Скелетная мышечная ткань пациента с врожденной миопатией центрального стержня (возраст 21 год). Гистохимическое выявление активности сукцинатдегидрогеназы нитро-СТ по Нахласу и др. (1957) криостатных срезов (препарат В. С. Сухорукова, х200). Почти во всех продольно срезанных мышечных волокнах определено полное отсутствие активности фермента в центральных зонах (показано стрелками) 
Показано, что дефицит селенопротеина $\mathrm{N}$ приводит к повышению оксидантной активности в миотубах и нарушению регуляции супероксиддисмутазы и каталазы. В результате происходит окислительный стресс, кальциевый гомеостаз мышечной ткани нарушается вследствие выхода из строя рианодиновых рецепторов и неконтролируемого высвобождения кальция через их каналы $[9,11,14]$. Мутации в гене SEPN1 связаны с развитием многостержневых миопатий (ОМІМ 602771), а также с врожденной мышечной дистрофией с ригидным позвоночником (Muscular dystrophy, rigid spine, 1, OMIM 602771), имеющей сходный фенотип [15]. Тип наследования заболеваний - аутосомно-рецессивный.

K гистологическим признакам многостержневых миопатий относят наличие в скелетно-мышечных волокнах множественного количества стержней, не обязательно расположенных центрально (рис. 3). Морфофункциональной особенностью строения мышечной ткани при RYR1-обусловленной многостержневой миопатии является наличие достаточно массивных стержней в мышечном волокне (multicores) [9, 11]. Характерная патоморфологическая особенность мышечной ткани при SEPN1-обусловленной многостержневой миопатии - наличие большого количества мелких стержней (minicores) [9, 11].

Многостержневая миопатия - врожденная миопатия с началом в раннем детском возрасте (симптомокомплекс «вялого ребенка»), характеризующаяся мышечной гипотонией, задержкой формирования двигательных навыков, выраженной мышечной слабостью в проксимальных отделах конечностей, деформациями позвоночника с ранним формированием сколиоза, деформацией грудной клетки. Для многостержневой миопатии характерна слабость лицевой мускулатуры.

Сходство клинических проявлений стержневых миопатий с другими видами врожденных миопатий, сложность структуры этих заболеваний, различные варианты сочетания нарушений мышечной ткани осложняют проведение их дифференциальной диагностики. Диагностика врожденных стержневых миопатий основана на сочетании клинических и морфологических признаков, а также данных молекулярногенетического исследования. Фенотип больных со структурными миопатиями, включая клинические симптомы и морфологическую картину (процессы, происходящие в мышечной ткани), не всегда однотипен. Несмотря на выявленную этиопатогенетическую связь с генами RYR1 и SEPN1, существует предположение о влиянии других генов на развитие заболевания, а также полигенной природы заболевания [2]. В связи с этим представляется актуальным изучение клинических, морфологических и генетических параллелей врожденных стержневых миопатий.

Цель настоящего исследования - сопоставить клинико-морфологические характеристики с результатами экзомного секвенирования, полученными методами массового параллельного секвенирования (MPS), у пациентов с клиническими и морфологическими признаками врожденных стержневых миопатий.

\section{ПАЦИЕНТЫ И МЕТОДЫ}

В исследование были включены 8 детей, среди которых 2 мальчика и 6 девочек (3-14 лет). Критерии включения пациентов в исследование: пациенты любого пола с неотягощенным семейным анамнезом; наличие диагноза врожденной миопатии; наличие морфологических признаков стержневой миопатии; наличие результатов молекулярно-генетического исследования. Критерии исключения: отсутствие морфологических признаков стержневых структур по данным биопсии.

Были проанализированы выписки из историй болезни пациентов. Морфологический анализ проводили с помощью световой микроскопии при помощи микроскопа Nikon Eclipse Ni (Nikon Corp.; Япония) (окраска парафиновых и замороженных срезов, гистоферментохимическая окраска) и электронной микроскопии согласно протоколам производителей.

1. Срезы свежей ткани получали путем заморозки биоптата в жидком азоте и дальнейшей нарезки на микротоме-криостате Microm HM 505 N (Microm Tech.; США). Для получения парафиновых срезов проводили химическую фиксацию в 10\%-м нейтральном (pH 7,4) забуференном формалине согласно протоколу производителя и дальнейшую нарезку на микротоме.

2. Окраску гематоксилином и эозином замороженных срезов, окраску гематоксилином и эозином парафиновых срезов, гистохимическое выявление активности сукцинатдегидрогеназы в замороженных срезах с использованием нитросинего тетразолия по Нахласу и др., 1957 [16] проводили согласно стандартному протоколу.

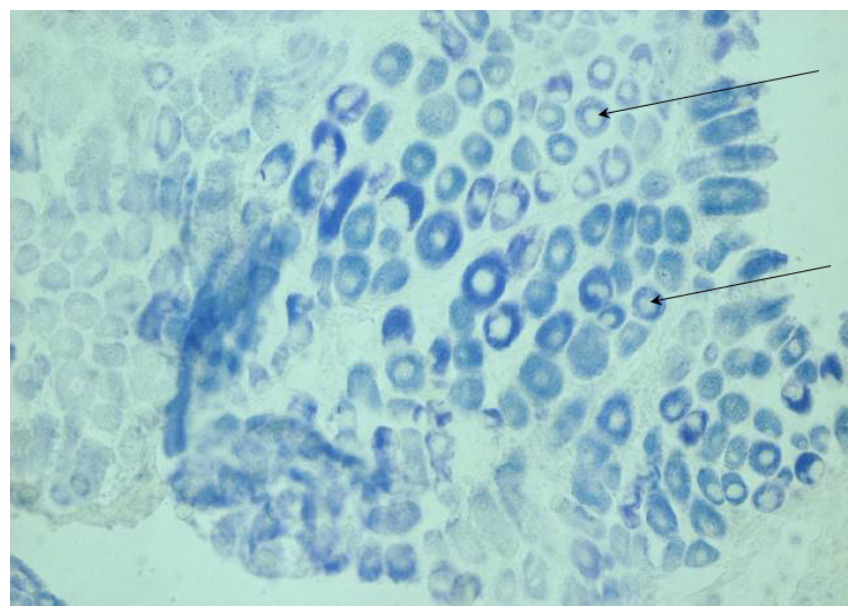

Рис. 2. Скелетная мышечная ткань пациента с врожденной миопатией центрального стержня (возраст 1 год). Гистохимическое выявление активности сукцинатдегидрогеназы нитро-СТ по Нахласу и др. (1957) криостатных срезов (×200). Почти во всех поперечно срезанных мышечных волокнах определено полное отсутствие активности фермента в центральных зонах (показано стрелками)

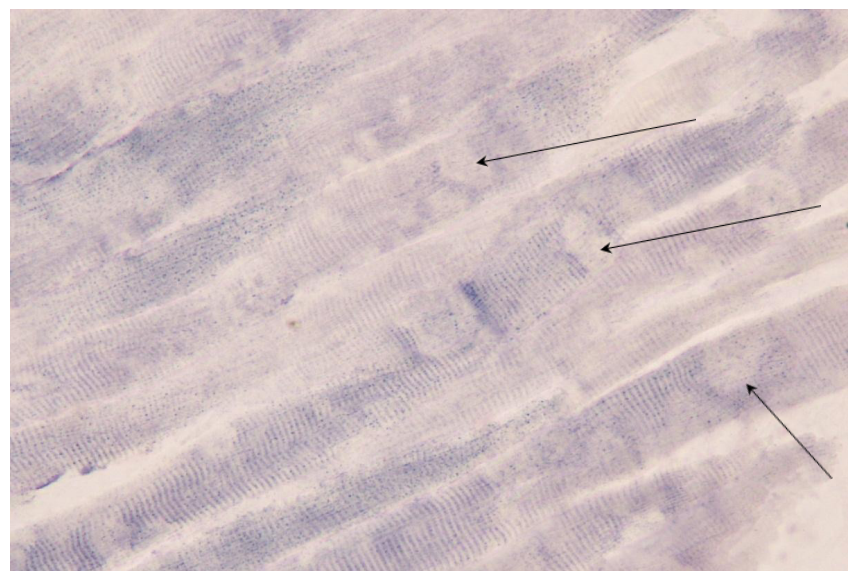

Рис. 3. Скелетная мышечная ткань пациента с врожденной многостержневой миопатией (возраст 3,5 года). Гистохимическое выявление активности сукцинатдегидрогеназы нитро-СТ по Нахласу и др. (1957) криостатных срезов (препарат В. С. Сухорукова, х200). Почти во всех продольно срезанных мышечных волокнах определен феномен множественных стержней (показано стрелками) 
3. Для электронно-микроскопического исследования проводили префиксацию материала размером не более 1 мм $^{3}$ в 2,5\%-м растворе глутарового альдегида на фосфратном бусрере $(\mathrm{pH} 7,4)$ при $0{ }^{\circ} \mathrm{C}$. После отмывки ткани фосффатным буфером (pH 7,4) фиксировали 1\%-м раствором четырехокиси осмия в течение часа при $2-4{ }^{\circ} \mathrm{C}$. Затем ткань обезвоживали в спиртах восходящей концентрации. Заливку ткани производили в эпоновую смолу после трехкратной обработки ацетоном по методике Лафта [17] согласно стандартному протоколу. Срезы получали на ультратоме REICHERT Nr. 321850/E (Reichert tech.; Австрия) и контрастировали цитратом свинца и уранил-ацетатом натрия по методике Рейнольдса [18]. Исследование проводили на трансмиссионном электронном микроскопе JEOL JEM-100B (Jeol LTD.; Япония).

Молекулярно-генетический анализ проводили с помощью MPS на платформе HiSeq2500 (Illumina; CША) согласно протоколу производителя.

1. Процедуру мечения ампликонов производили при помощи наборов для мечения BigDye Terminator v3.1 Cycle Sequencing Kit (Thermo Fisher Scientific; США) по протоколу производителя. Секвенирование по Сэнгеру на генетическом анализаторе ABI PRISM 3500 Genetic Analyzer (Applied Biosystems; США) согласно протоколу производителя.

2. Биоинформатическую обработку данных MPS проводили при помощи Cutadapt версии 1.14 (Cutadapt; США), BWA версии 1.14 (Illumina; CША), FastQC версии 0.11 .5 (Illumina; CШA), GATK HaplotypeCaller версии 3.7 (GATK HaplotypeCaller; CШA), snpEff версии 4.3p (SnpEff; CШA). Оценивали патогенность и консервативность, данные для которых извлекали из баз данных dbNSFP, Clinvar, OMIM и HGMD; использовали также утилит SIFT версии 1.03 (SIFT; США) и Polyphen2 версии 2.2.2 (Polyphen2; США) для предсказания возможной патогенности мутации. Информация о частотах мутаций взята из баз данных 1000Genomes project, ExAC и др. Аннотацию мутаций и их патогенность предсказывали согласно Стандартам и Руководству, разработанным ACMG, AMP и CAP для интерпретации мутаций, полученных с помощью секвенирования [19].

3. Клиническую интерпретацию результатов молекулярногенетического анализа (экзомного секвенирования) проводили с помощью генетических баз данных ОМIM (https://omim.org/), Varsome (https://varsome.com/), ClinVar (https://www.ncbi.nlm.nih.gov/clinvar/), The Human Gene Mutation Database (http://www.hgmd.cf.ac.uk/ac/index. php) и др., согласно руководству по интерпретации данных, полученных методами массового параллельного секвенирования (MPS) [20].

\section{РЕЗУЛЬТАТЫ ИССЛЕДОВАНИЯ}

У обследованных больных было отмечено наличие сходных клинических проявлений, характерных для врожденных структурных миопатий: симптомокомплекс «вялого ребенка» в раннем возрасте, задержка формирования моторных навыков. Выявлены различная степень нарушения походки (вплоть до отсутствия самостоятельной ходьбы) и деформации позвоночника; в неврологическом статусе обращали на себя внимание снижение мышечной силы и тонуса, снижение или отсутствие сухожильных рефлексов с верхних и нижних конечностей. При биохимическом обследовании уровень креатинфосфокиназы (КФК) у троих детей в возрасте до 5 лет был нормальным, а у пяти пациентов в возрасте 7-14 лет находился на верхних границах нормы или был незначительно повышен (табл. 1). У всех детей при морфологическом обследовании выявлены стержневые структуры мышечного волокна у пяти пациентов (пациенты 1, 2, 3, 7, 8) отмечена картина болезни центрального стержня, у трех пациентов (пациенты 4, 5, 6) - картина многостержневой миопатии.

Мутации были обнаружены в 87,5\% случаев (у 7 из 8 обследованных пациентов): у 6 обследованных - в генах RYR1 и SEPN1, ответственных за врожденные стержневые миопатии, и у одного пациента - в гене LAMA2, ответственном за мерозин-негативную мышечную дистросиюю (табл. 2).

\section{ОБСУЖДЕНИЕ РЕЗУЛЬТАТОВ}

Результаты молекулярно-генетического анализа достаточно хорошо коррелируют с клиническими и морфологическими данными пациентов: у троих пациентов с морфологической картиной болезни центрального стержня (пациенты 1, 2 и 3) выявлены мутации в гене RYR1, у троих пациентов с морфологической картиной многостержневой миопатии (пациенты 4, 5 и 6) выявлены мутации в гене SEPN1 (табл. 2). Доли пациентов с мутациями в генах RYR1 и SEPN1 одинаковы и составляют 42,86\% для каждого гена среди пациентов с мутациями.

В гене RYR1 обнаружено 4 мутации у троих пациентов. Три выявленные мутации с.11798A>G, с.14387A>G и c.14581C>T описаны ранее [21, 22, 23].

Согласно литературным данным, мутации с.11798A>G и c.14387A>G ассоциированы со спорадическими случаями болезни центрального стержня и у наших пациентов (1-го и 2-го соответственно) также выявлены в гетерозиготном состоянии.

У пациента 3 выявлены две мутации (с.14581С>Т и c.7561G>A) в гене RYR1 предположительно в компаундгетерозиготном состоянии, что позволяет думать об аутосомно-рецессивном типе наследования заболевания. Мутация с.14581C>T описана и при спорадических случаях, и как рецессивный аллель [27]. Мутация с.7561G>A идентифицирована впервые. Наличие двух мутаций позволяет предполагать аутосомно-рецессивный тип наследования.

В гене SEPN1 обнаружено 4 мутации у троих пациентов. Мутации с.611dupA, с.713dupA, с.583G>A были описаны ранее [24, 25].

Мутация c.611dupA представляет собой мутацию сдвига рамки считывания (frameshift), приводящую к синтезу укороченного нефункционального белка. Данная мутация обнаружена в гомозиготном состоянии (пациент 5), что согласуется с аутосомно-рецессивным типом наследования заболевания.

Мутация c.713dupA, также являющаяся мутацией типа frameshift, выявлена у пациента 4 в компаунд-гетерозиготном состоянии. Она описана как причина Muscular dystrophy, rigid spine, 1 (ОМІМ: 602771) у фрранцузских пациентов и в гомозиготном, и в гетерозиготном состояниях [24]. Выявленный у пациента 4 генетический вариант с.583G>A, расцененный предсказательными программами как вероятно патогенный, описан в базах данных мутаций как доброкачественный, однако его значимость для развития заболевания пациента необходимо дополнительно исследовать.

Мутация с.485C>A идентифицирована впервые и обнаружена в гетерозиготном состоянии (пациент 6). Это не 
позволяет подтвердить диагноз многостержневой миопатии, хотя морфологические и клинические данные пациента согласуются с данным диагнозом. Исключить диагноз многостержневой миопатии, обусловленной мутациями в гене SEPN1, мы тоже не можем, так как мутация во втором аллеле гена могла быть не найдена в связи с техническими ограничениями метода высокопроизводительного параллельного секвенирования.

У двух пациентов с направляющим диагнозом врожденной миопатии/миодистрофии и морфологическими признаками болезни центрального стержня (пациенты 7 и 8) не были выявлены мутации в генах RYR1 и SEPN1.

У пациента 7 обнаружено две мутации предположительно в компаунд-гетерозиготном состоянии в гене LAMA2 (14,28\% случаев с выявленными мутациями). Мутации в гене LAMA2 связаны с развитием поясно-конечностной мышечной дистрофии 23-го типа (ОМІМ 618138) и с врожденной мерозин-негативной мышечной дистрофией (ОМІМ 607855), наследующихся аутосомно-рецессивно.

Выявленная у пациента 7 мутация в гене LAMA2 c.7147C>T (p.Arg2383*), приводящая к синтезу укороченного нефункционального белка, описана ранее в гомозиготном состоянии у девочки 4-х лет [28], с характерными для мерозин-десицитной врожденной мышечной дистрофии типа А признаками (врожденная гипотония, мышечная слабость, высокий уровень сывороточной креатинкиназы (1556 ME/л) и аномалии белого вещества при магнитнорезонансной томографии). Кроме того, у пациентов с этим заболеванием могут отмечаться судороги и структурные аномалии головного мозга. Причины вариабельной тяжести клинического фенотипа при врожденной мышечной дистрофии с частичным дефицитом ламинина альфа 2 до конца не известны и могут быть обусловлены нарушениями сайта сплайсинга [26].

Вторая мутация в гене LAMA2, выявленная у нашей пациентки, - несинонимичная замена с.3406T>C (p.Cys1136Arg) - не описана. Несинонимичные замены могут приводить как к формированию альтернативных сайтов сплайсинга и синтезу новых изоформ белка, так и к конформационным изменениям структуры белка, нарушающим его функцию. В связи с этим необходимы дальнейшие исследования для уточнения роли обнаруженной мутации в развитии заболевании.

У нашей пациентки клиническая картина была отличной от описанной выше и неоднозначной. Дифференциальную диагностику проводили между спинальной мышечной

Таблица 1. Выявленные симптомы пациентов с морфологическими признаками стержневой миопатии

\begin{tabular}{|c|c|c|c|c|c|c|c|c|}
\hline $\begin{array}{c}\text { Симптомы / } \\
\text { Пациент }\end{array}$ & 1 & 2 & 3 & 4 & 5 & 6 & 7 & 8 \\
\hline $\begin{array}{c}\text { Показатели } \\
\text { массы и роста } \\
\text { при рождении } \\
\text { (г/см) }\end{array}$ & $3310 / 50$ & $3540 / 55$ & $2480 / 48$ & $2800 / 49$ & $3780 / 53$ & $3060 / 50$ & $2859 / 50$ & $3500 / 54$ \\
\hline $\begin{array}{c}\text { Врожденный } \\
\text { вывих/дисплазия } \\
\text { бедра }\end{array}$ & - & - & + (вывих) & - & - & - & + (дисплазия) & - \\
\hline $\begin{array}{c}\text { Отставание в } \\
\text { формировании } \\
\text { моторных } \\
\text { навыков }\end{array}$ & - & + & + & + & + & - & ++ & + \\
\hline Сила мышц & 4 балла & 4 балла & 4 балла & 2-3 балла & 4 балла & 2-3 балла & 1-2 балла & 3-4 балла \\
\hline Походка & Миопатическая & Не ходит & Миопатическая & Миопатическая & Миопатическая & $\begin{array}{l}\text { Не ходит с } \\
9 \text { лет }\end{array}$ & $\begin{array}{c}\text { Никогда не } \\
\text { ходила }\end{array}$ & Миопатическая \\
\hline $\begin{array}{c}\text { Поражение } \\
\text { позвоночника }\end{array}$ & $\begin{array}{l}\text { Кифоз } \\
\text { грудного } \\
\text { отдела }\end{array}$ & $\begin{array}{l}\text { Кифоз } \\
\text { грудного } \\
\text { отдела }\end{array}$ & $\begin{array}{l}\text { Искривление } \\
\text { позвоночника }\end{array}$ & $\begin{array}{c}\text { Сколиоз } \\
\text { грудного и } \\
\text { поясничного } \\
\text { отделов }\end{array}$ & $\begin{array}{c}\text { Ригидность } \\
\text { позвоночника }\end{array}$ & Кифосколиоз & Сколиоз & Сколиоз \\
\hline $\begin{array}{c}\text { Наличие } \\
\text { контрактуры } \\
\text { суставов }\end{array}$ & $\begin{array}{c}\text { Голеностопных } \\
\text { суставов }\end{array}$ & - & - & $\begin{array}{c}\text { Тазобедреных, } \\
\text { коленных, } \\
\text { голеностопных } \\
\text { суставов }\end{array}$ & $\begin{array}{l}\text { Голеностопных } \\
\text { суставов }\end{array}$ & $\begin{array}{c}\text { Тазобедренных, } \\
\text { коленных, } \\
\text { голеностопных } \\
\text { суставов }\end{array}$ & $\begin{array}{c}\text { Тазобедренных, } \\
\text { коленных, } \\
\text { локтевых, } \\
\text { голеностопных, } \\
\text { луче-запястных } \\
\text { суставов }\end{array}$ & $\begin{array}{c}\text { Тазобедренных, } \\
\text { коленных, } \\
\text { голеностопных } \\
\text { суставов }\end{array}$ \\
\hline $\begin{array}{c}\text { Снижение } \\
\text { рефлексов } \\
\text { верхних } \\
\text { и нижних } \\
\text { конечностей }\end{array}$ & + & + & + & ++ & + & ++ & ++ & ++ \\
\hline $\begin{array}{c}\text { Нарушение } \\
\text { дыхания }\end{array}$ & + & +- & нет данных & +++ & + & + & нет данных & + \\
\hline $\begin{array}{c}\text { Снижение } \\
\text { интеллекта }\end{array}$ & - & + & +- & - & - & - & - & - \\
\hline $\begin{array}{c}\text { Дополнительные } \\
\text { признаки }\end{array}$ & - & - & - & $\begin{array}{c}\text { Недостаточность } \\
\text { питания } \\
\text { тяжелой } \\
\text { степени }\end{array}$ & - & $\begin{array}{c}\text { Птоз верхнего } \\
\text { века, } \\
\text { хроническая } \\
\text { гиповентиляция }\end{array}$ & $\begin{array}{c}\text { Слабость } \\
\text { лицевой } \\
\text { мускулатуры, } \\
\text { затылочная } \\
\text { эпилепсия }\end{array}$ & - \\
\hline $\begin{array}{c}\text { Уровень } \\
\text { КФК, ед/л } \\
\text { (норма 15-190) }\end{array}$ & 78 & 66 & 79 & 188 & 284 & 174 & 290 & 194 \\
\hline
\end{tabular}

Примечание: 1 - мальчик, 4 года; 2 - девочка, 3 года; 3 - девочка, 5 лет; 4 - девочка, 8 лет; 5 - мальчик, 7 лет; 6 - девочка, 11 лет; 7 - девочка, 14 лет; 8 - девочка, 7 лет. 
Таблица 2. Спектр выявленных мутаций у пациентов с морфологическими признаками стержневой миопатии

\begin{tabular}{|c|c|c|c|c|c|c|c|c|}
\hline \multirow[b]{2}{*}{ Пациент } & \multirow{2}{*}{$\begin{array}{c}\text { Диагноз, поставленный } \\
\text { при направлении на } \\
\text { исследование }\end{array}$} & \multirow[b]{2}{*}{ Ген } & \multicolumn{5}{|c|}{ Выявленные мутации, генотипы } & \multirow{2}{*}{$\begin{array}{c}\text { Ссылки на } \\
\text { публикации }\end{array}$} \\
\hline & & & $\begin{array}{c}\text { № } \\
\text { экзона }\end{array}$ & $\begin{array}{c}\text { № } \\
\text { транскрипта }\end{array}$ & Нуклеотид & $\begin{array}{c}\text { Аминокислотная } \\
\text { замена }\end{array}$ & Генотип & \\
\hline 1 & $\begin{array}{c}\text { Врожденная структурная } \\
\text { миопатия. Болезнь } \\
\text { центрального стержня }\end{array}$ & $R Y R 1,19 \mathrm{q} 13.2$ & 86 & NM_000540.2 & c. $11798 A>G$ & p.Tyr3933Cys & Гетерозигота & [21] \\
\hline 2 & Врожденная миопатия & $R Y R 1,19 \mathrm{q} 13.2$ & 100 & NM_000540.2 & c. $14387 A>G$ & p.Tyr4796Cys & Гетерозигота & [22] \\
\hline \multirow{2}{*}{3} & \multirow{2}{*}{$\begin{array}{c}\text { Врожденная структурная } \\
\text { миопатия }\end{array}$} & \multirow{2}{*}{$R Y R 1,19 \mathrm{q} 13.2$} & 101 & NM_000540.2 & c. $14581 C>T$ & p.Arg4861Cys & Гетерозигота & [23] \\
\hline & & & 47 & NM_000540.2 & c. $7561 \mathrm{G}>\mathrm{A}$ & p.Val2521Met & Гетерозигота & Не описана \\
\hline \multirow{2}{*}{4} & \multirow{2}{*}{ Врожденная миопатия } & \multirow{2}{*}{ SEPN1, 1p36.11 } & 5 & NM_020451.2 & c.713dupA & p.Asn238fs & Гетерозигота & [24] \\
\hline & & & 5 & NM_020451.2 & c. $583 \mathrm{G}>\mathrm{A}$ & p.Ala195Thr & Гетерозигота & [25] \\
\hline 5 & Врожденная миопатия & SEPN1, $1 \mathrm{p} 36.11$ & 4 & NM_206926.1 & c.611dupA & p.Asn204fs & Гомозигота & [24] \\
\hline 6 & Врожденная миопатия & SEPN1, 1p36.11 & 4 & NM_206926.1 & c. $485 \mathrm{C}>\mathrm{A}$ & p.Ser162* & Гетерозигота & Не описана \\
\hline \multirow{2}{*}{7} & \multirow{2}{*}{$\begin{array}{c}\text { Врожденная структурная } \\
\text { миопатия }\end{array}$} & \multirow{2}{*}{ LAMA2, 6q22.33 } & 50 & NM_000426.3 & c. $7147 \mathrm{C}>\mathrm{T}$ & p.Arg2383* & Гетерозигота & {$[26,28]$} \\
\hline & & & 23 & NM_000426.3 & c. $3406 \mathrm{~T}>\mathrm{C}$ & p.Cys1136Arg & Гетерозигота & Не описана \\
\hline 8 & $\begin{array}{c}\text { Врожденная мышечная } \\
\text { дистрофия }\end{array}$ & - & - & - & Не выявлено & Не выявлено & Не известен & - \\
\hline
\end{tabular}

Примечание: 1 - мальчик, 4 года; 2 - девочка, 3 года; 3 - девочка, 5 лет; 4 - девочка, 8 лет; 5 - мальчик, 7 лет; 6 - девочка, 11 лет; 7 - девочка, 14 лет; 8 - девочка, 7 лет; * - стоп-кодон.

атросиией Верднига-Гоффрманна и врожденными структурными миопатиями. Эпилепсия носила доброкачественный характер и не была учтена как один из признаков заболевания. Морфологическая картина мышечного биоптата соответствовала болезни центрального стержня. Тем не менее сочетание клинических, морфологических и молекулярно-генетических данных у описанной нами пациентки 7 нельзя считать однозначно противоречивым. До настоящего времени механизм и время появления стержневых структур, обнаруживаемых при морфологическом исследовании, до конца не изучены [2]. Предполагают, что это преимущественно обусловлено нарушением функциональной активности митохондрий. Изучение биоптатов мышечной ткани при различных формах врожденных миопатий/миодистрофий на разных стадиях патологического процесса возможно расширит представления о взаимодействиях и последовательности вовлечения различных белков и структур мышечной ткани в патологический процесс.

У пациента 8 не было выявлено клинически значимых генетических вариантов в генах, связанных с развитием нервно-мышечных заболеваний, однако это может быть обусловлено техническими ограничениями метода высокопроизводительного секвенирования.

Отсутствие мутаций в гене RYR1 у двух пациентов (пациенты 7 и 8) с направляющим диагнозом врожденной миопатии/миодистрофии и морфологическими признаками центрального стержня подтверждает необходимость проведения расширенного молекулярно-генетического исследования этой подгруппы пациентов. В то же время при наличии дополнительных клинических симптомов, редких для определенного заболевания (в нашем случае у пациента 7 - наличие судорог), вероятность выявления иных молекулярно-генетических нарушений повышается. Это так же подтверждает необходимость проведения исследований, направленных на изучение патогенетических механизмов и их морфологических проявлений при врожденных миопатиях и миодистрофических процессах.

Были также выявлены корреляции между значениями активности КФК и обнаруженными мутациями. Уровень КФК, как правило, позволяет предположить локализацию поражения при нервно-мышечных заболеваниях и свидетельствует об остроте и длительности патологического процесса при поражении мышц. Мутации в гене RYR1 обнаружены только у пациентов с нормальным уровнем КФК. Наибольшее повышение уровня данного фермента выявлено у пациента с frameshift-мутацией в гомозиготном состоянии в гене SEPN1 и у пациента с мутациями в гене LAMA2, ассоциированном с наиболее тяжелой формой врожденной миопатии. Возможно, что уровень КФК служит своеобразным маркером патогенности молекулярно-генетического нарушения (степени влияния на наличие и функцию белкового продукта гена), приводящего к развитию заболевания и возникновению вторичных миодистрофических процессов.

\section{ВЫВОДЫ}

Полученные результаты еще раз подтверждают генетическую гетерогенность миопатий, характеризующихся наличием морфологической картины стержневых структур мышечных волокон. Основными генетическими причинами развития стержневых миопатий у российских пациентов являются мутации в гене RYR1 и гене SEPN1, что согласуется с результатами зарубежных исследований. Большинство мутаций - 75\% (6 пациентов из 8), выявленных у наших пациентов в этих двух генах, описаны ранее. Две мутации, обнаруженные нами впервые, требуют дальнейшего исследования для уточнения их клинического значения. Показано также, что морфологическая картина мышечного волокна не может служить единственным критерием дифференциальной диагностики врожденных миопатий. Морфологические признаки стержневых миопатий могут быть выявлены и при других формах врожденных миопатий/ миодистросфий. Это свидетельствует о необходимости дальнейшего изучения клинических, морфологических и генетических корреляций для понимания патогенетических механизмов, что может быть важно при разработке эффективных методов терапии осложнений заболеваний. Отсутствие у пациентов с клинико-морфологической картиной стержневых миопатий мутаций в генах, ответственных за развитие врожденных миопатий, требует дальнейшего изучения. 


\section{Литература}

1. Bonne G, Rivier F, Hamroun D. The 2019 version of the gene table of neuromuscular disorders (nuclear genome). Neuromuscul Disord. 2018 Dec; 28 (12): 1031-63. DOI: 10.1016/j.nmd.2018.09.006.

2. Сухоруков В. С., Харламов Д. А. Врожденные миопатии. М. ООО Пресс-Арт, 2010; 155 c.

3. Jungbluth $H$, Sewry CA, Muntoni F. Core Myopathies. Semin Pediatr Neurol. 2011 Dec; 18 (4): 239-49. DOI: 10.1016/j. spen.2011.10.005.

4. Харламов Д. А., Баранич Т. И., Глинкина В. В., Брыдун А. В. Митохондриальные нарушения при врожденных миопатиях Российский вестник перинатологии и педиатрии. 2014; 59 (3): 32-38.

5. MacLennan DH, Zorzato F, Fujii J, Otsu K, Phillips M, Lai FA, et al. Cloning and localization of the human calcium release channel (ryanodine receptor) gene to the proximal long arm (cen-q13.2) of human chromosome 19. (Abstract) Am J Hum Genet [Internet]. 1989; 45 (suppl.).

6. Moghadaszadeh B, Petit N, Jaillard C, Brockington M, Roy SQ, Merlini L, et al. Mutations in SEPN1 cause congenital muscular dystrophy with spinal rigidity and restrictive respiratory syndrome. Nature Genet. 2001; (29): 17-8.

7. Мельников К. Н. Разнообразие и свойства кальциевых каналов возбудимых мембран. Психофармакология и биологическая наркология. 2006; (1-2): 1139-51.

8. Chen W, Koop A, Liu Y, Guo W, Wei J, Wang R, et al. Reduced threshold for store overload-induced $\mathrm{Ca}^{2+}$ release is a common defect of RyR1 mutations associated with malignant hyperthermia and central core disease. Biochem J. 2017 Aug 7; 474 (16): 2749-61. DOI: 10.1042/BCJ20170282. PMID: 28687594.

9. Сухоруков В. С., Харламов Д. А., Шаталов П. А., Харабадзе М. Н., Яблонская М. И., Брыдун А. В. и др. Врожденная «многостержневая» миопатия. Российский вестник перинатологии и педиатрии. 2012; 57 (4-1): 90-3.

10. Jungbluth $\mathrm{H}$, Zhou $\mathrm{H}$, Hartley L, Halliger-Keller B, Messina S, Longman C, et al. Minicore myopathy with ophthalmoplegia caused by mutations in the ryanodine receptor type 1 gene. Neurology. 2005 Dec 27; 65 (12): 1930-5. PMID: 16380615.

11. Jungbluth $\mathrm{H}$. Multi-minicore Disease. Orphanet J Rare Dis. 2007; (2): 31-45.

12. McCarthy EJ. Malignant hyperthermia: pathophysiology, clinical presentation, and treatment. AACN Clin Issues. 2004 Apr-Jun; 15 (2): 231-7. PMID: 15461040.

13. Сухоруков В. С., Шаталов П. А., Харламов Д. А., Брыдун А. В. Изменения митохондрий при врожденной миопатии «центрального стержня» у детей. Российский вестник перинатологии и педиатрии. 2011; 56 (4): 84-7.

14. Lescure A, Rederstorff M, Krol A, et al. Selenoprotein function and muscle disease. Biochim Biophys Acta. 2009; (1790): 1569-74.

15. Engel AG, Gomes MR. Congenital myopathy associated with multifocal degeneration of muscle fibers. Trans Am Neurology Assoc. 1966; (91): 222-3.

\section{References}

1. Bonne G, Rivier F, Hamroun D. The 2019 version of the gene table of neuromuscular disorders (nuclear genome). Neuromuscul Disord. 2018 Dec; 28 (12): 1031-63. DOI: 10.1016/j.nmd.2018.09.006.

2. Suhorukov VS, Harlamov DA. Vrozhdennye miopatii. M.: 000 Press-Art, 2010; 155 s.

3. Jungbluth H, Sewry CA, Muntoni F. Core Myopathies. Semin Pediatr Neurol. 2011 Dec; 18 (4): 239-49. DOl: 10.1016/j. spen.2011.10.005

4. Harlamov DA, Baranich TI, Glinkina W, BrydunAV. Mitohondrial'nye narushenija pri vrozhdennyh miopatijah. Rossijskij vestnik perinatologii i pediatrii. 2014; 59 (3): 32-38.

5. MacLennan DH, Zorzato F, Fujii J, Otsu K, Phillips M, Lai FA, et al Cloning and localization of the human calcium release channel (ryanodine receptor) gene to the proximal long arm (cen-q13.2) of
16. Пирс Э. Гистохимия. М.: Изд-во иностранной литературы, 1962; $963 \mathrm{c.}$

17. Luft JH. Improvements in epoxy resin embedding methods. J Biophys Biochem Cytol. 1961; (9): 409-14.

18. Reynolds ES. The use of lead citrate at high $\mathrm{pH}$ as an electronopaque stain in electron microscopy. J Cell Biol. 1963; (17): 208-12.

19. Richards S, Aziz N, Bale S, Bick D, Das S, Gastier-Foster J. et al. Standards and guidelines for the interpretation of sequence variants: a joint consensus recommendation of the American College of Medical Genetics and Genomics and the Association for Molecular Pathology. Genet Med. 2015;17 (5): 405-23.

20. Рыжкова О. П., Кардымон О. Л., Прохорчук Е. Б., Коновалов Ф. А., Масленников А. Б., Степанов В. А. и др. Руководство по интерпретации данных, полученных методами массового параллельного секвенирования (MPS). Медицинская генетика. 2017; 16 (7): 4-17.

21. Duarte ST, Oliveira J, Santos R, Pereira P, Barroso C, Conceição I, et al. Dominant and recessive RYR1 mutations in adults with core lesions and mild muscle symptoms. Muscle Nerve. $2011 \mathrm{Jul} ; 44$ (1): 102-8. DOI: 10.1002/mus.22009. PMID: 21674524.

22. Monnier N, Romero NB, Lerale J, Nivoche Y, Qi D, MacLennan DH, et al. An autosomal dominant congenital myopathy with cores and rods is associated with a neomutation in the RYR1 gene encoding the skeletal muscle ryanodine receptor. Hum Mol Genet. 2000 Nov 1; 9 (18): 2599-608. PMID: 11063719.

23. Davis MR, Haan E, Jungbluth $H$, Sewry $C$, North K, Muntoni F, et al. Principal mutation hotspot for central core disease and related myopathies in the C-terminal transmembrane region of the RYR1 gene. Neuromuscul Disord. 2003 Feb; 13 (2): 151-7. PMID: 12565913.

24. Ferreiro A, Quijano-Roy S, Pichereau C, Moghadaszadeh B, Goemans N, Bönnemann C, et al. Mutations of the seleno-protein $\mathrm{N}$ gene, which is implicated in rigid spine muscular dystrophy, cause the classical phenotype of multiminicore disease: reassessing the nosology of early-onset myopathies. Am J Hum Genet. 2002 Oct; 71 (4): 739-49. PMID: 12192640.

25. Tajsharghi H, Darin N, Tulinius M, Oldfors A. Early onset myopathy with a novel mutation in the Selenoprotein $\mathrm{N}$ gene (SEPN1). Neuromuscul Disord. 2005 Apr; 15 (4): 299-302. PMID: 15792869.

26. Pegoraro E, Fanin M, Trevisan CP, Angelini C, Hoffman EP. A novel laminin alpha 2 isoform in severe laminin alpha 2 deficient congenital muscular dystrophy. Neurology. 2000 Oct 24; 55 (8): 1128-34. PMID: 11071490.

27. Kossugue PM, Paim JF, Navarro MM, Silva HC, Pavanello RC, Gurgel-Giannetti J, et al. Central core disease due to recessive mutations in RYR1 gene: is it more common than described? Muscle Nerve. 2007 May; 35 (5): 670-4. PMID: 17226826.

28. He Z, LuoX, Liang L, Li P, Li D, Zhe M. Merosin-deficient congenital muscular dystrophy type 1A: A case report. Exp Ther Med. 2013 Nov; 6 (5): 1233-6. PMID: 24223650.

human chromosome 19. (Abstract) Am J Hum Genet [Internet] 1989; 45 (suppl.)

6. Moghadaszadeh B, Petit N, Jaillard C, Brockington M, Roy SQ, Merlini L, et al. Mutations in SEPN1 cause congenital muscular dystrophy with spinal rigidity and restrictive respiratory syndrome. Nature Genet. 2001; (29): 17-8.

7. Melnikov KN. Raznoobrazie i svojstva kal'cievyh kanalov vozbudimyh membran. Psihofarmakologija i biologicheskaja narkologija. 2006; (1-2): 1139-51.

8. Chen W, Koop A, Liu Y, Guo W, Wei J, Wang R, et al. Reduced threshold for store overload-induced $\mathrm{Ca}^{2+}$ release is a common defect of RyR 1 mutations associated with malignant hyperthermia and central core disease. Biochem J. 2017 Aug 7; 474 (16): 2749-61. DOI: 10.1042/BCJ20170282. PMID: 28687594. 
9. Suhorukov VS, Harlamov DA, Shatalov PA, Harabadze MN, Yablonskaya MI, Brydun AV i dr. Vrozhdennaja «mnogosterzhnevaja» miopatija. Rossijskij vestnik perinatologii i pediatrii. 2012; 57 (4-1): 90-3.

10. Jungbluth $H$, Zhou $H$, Hartley L, Halliger-Keller B, Messina $S$, Longman $\mathrm{C}$, et al. Minicore myopathy with ophthalmoplegia caused by mutations in the ryanodine receptor type 1 gene. Neurology. 2005 Dec 27; 65 (12): 1930-5. PMID: 16380615.

11. Jungbluth H. Multi-minicore Disease. Orphanet J Rare Dis. 2007; (2): $31-45$.

12. McCarthy EJ. Malignant hyperthermia: pathophysiology, clinical presentation, and treatment. AACN Clin Issues. 2004 Apr-Jun; 15 (2): 231-7. PMID: 15461040.

13. Suhorukov VS, Shatalov PA, Harlamov DA, Brydun AV. Izmenenija mitohondrij pri vrozhdennoj miopatii "Central'nogo sterzhnja" $u$ detej. Rossijskij vestnik perinatologii i pediatrii. 2011; 56 (4): 84-7.

14. Lescure A, Rederstorff M, Krol A, et al. Selenoprotein function and muscle disease. Biochim Biophys Acta. 2009; (1790): 1569-74.

15. Engel AG, Gomes MR. Congenital myopathy associated with multifocal degeneration of muscle fibers. Trans Am Neurology Assoc. 1966; (91): 222-3.

16. Pirs A. Gistohimiya. M.: Izd-vo inostrannoj literatury, 1962; $963 \mathrm{~s}$.

17. Luft $\mathrm{JH}$. Improvements in epoxy resin embedding methods. J Biophys Biochem Cytol. 1961; (9): 409-14.

18. Reynolds ES. The use of lead citrate at high $\mathrm{pH}$ as an electronopaque stain in electron microscopy. J Cell Biol. 1963; (17): 208-12.

19. Richards S, Aziz N, Bale S, Bick D, Das S, Gastier-Foster J. et al. Standards and guidelines for the interpretation of sequence variants: a joint consensus recommendation of the American College of Medical Genetics and Genomics and the Association for Molecular Pathology. Genet Med. 2015;17 (5): 405-23.

20. Ryzhkova OP, Kardymon OL, Prohorchuk EB, Konovalov FA, Maslennikov AB, Stepanov VA i dr. Rukovodstvo po interpretacii dannyh, poluchennyh metodami massovogo parallel'nogo sekvenirovanija (MPS). Medicinskaja genetika. 2017; 16 (7): 4-17.
21. Duarte ST, Oliveira J, Santos R, Pereira P, Barroso C, Conceição I, et al. Dominant and recessive RYR1 mutations in adults with core lesions and mild muscle symptoms. Muscle Nerve. $2011 \mathrm{Jul} ; 44$ (1): 102-8. DOI: 10.1002/mus.22009. PMID: 21674524.

22. Monnier N, Romero NB, Lerale J, Nivoche Y, Qi D, MacLennan DH, et al. An autosomal dominant congenital myopathy with cores and rods is associated with a neomutation in the RYR1 gene encoding the skeletal muscle ryanodine receptor. Hum Mol Genet. 2000 Nov 1; 9 (18): 2599-608. PMID: 11063719.

23. Davis MR, Haan E, Jungbluth H, Sewry C, North K, Muntoni F, et al. Principal mutation hotspot for central core disease and related myopathies in the C-terminal transmembrane region of the RYR1 gene. Neuromuscul Disord. 2003 Feb; 13 (2): 151-7. PMID: 12565913.

24. Ferreiro A, Quijano-Roy S, Pichereau C, Moghadaszadeh B, Goemans N, Bönnemann C, et al. Mutations of the seleno-protein $\mathrm{N}$ gene, which is implicated in rigid spine muscular dystrophy, cause the classical phenotype of multiminicore disease: reassessing the nosology of early-onset myopathies. Am J Hum Genet. 2002 Oct; 71 (4): 739-49. PMID: 12192640.

25. Tajsharghi H, Darin N, Tulinius M, Oldfors A. Early onset myopathy with a novel mutation in the Selenoprotein $\mathrm{N}$ gene (SEPN1). Neuromuscul Disord. 2005 Apr; 15 (4): 299-302. PMID: 15792869.

26. Pegoraro E, Fanin M, Trevisan CP, Angelini C, Hoffman EP. A novel laminin alpha 2 isoform in severe laminin alpha 2 deficient congenital muscular dystrophy. Neurology. 2000 Oct 24; 55 (8): 1128-34. PMID: 11071490.

27. Kossugue PM, Paim JF, Navarro MM, Silva HC, Pavanello RC, Gurgel-Giannetti J, et al. Central core disease due to recessive mutations in RYR1 gene: is it more common than described? Muscle Nerve. 2007 May; 35 (5): 670-4. PMID: 17226826.

28. He Z, Luo X, Liang L, Li P, Li D, Zhe M. Merosin-deficient congenital muscular dystrophy type 1A: A case report. Exp Ther Med. 2013 Nov; 6 (5): 1233-6. PMID: 24223650. 